\title{
Síndrome de Schnitzler relacionado con gammapatía monoclonal IgG: ¿caso inusual?
}

\section{Schnitzler syndrome associated with monoclonal IgG gammopathy: unusual case?}

Lina P. González-Cardona1*, Natalia Muñoz-Angulo² y M. Isabel Moreno-Pedraza ${ }^{1,3}$

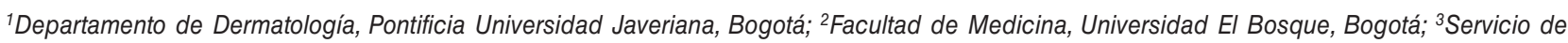
dermatología, Clínicos, Bogotá. Colombia

\begin{abstract}
Resumen
El síndrome de Schnitzler es una enfermedad autoinflamatoria caracterizada por fiebre periódica, síntomas inflamatorios sistémicos, lesiones urticariformes y gammapatía monoclonal. Se presenta el caso clínico de un hombre en la quinta década de la vida con cuadro clínico consistente en lesiones urticariformes y fiebre, tratado como una urticaria crónica resistente a antihistamínicos en la cual los estudios de extensión por dermatología, reumatología y hematología identificaron reactantes de fase aguda elevados y gammapatía monoclonal lgG.
\end{abstract}

Palabras clave: Síndrome de Schnitzler. Enfermedad autoinflamatoria. Gammapatía monoclonal IgG.

\section{Abstract}

Schnitzler syndrome is an autoinflammatory disease characterized by periodic fever, systemic inflammatory symptoms, urticarial lesions, and monoclonal gammopathy. We present the clinical case of a man in the fitth decade of life with clinic of urticarial lesions and fever treated as chronic urticaria that has not response to antihistamines, the complementary studies made by dermatology, rheumatology and hematology revealed acute phase reactants elevated and IgG monoclonal gammopathy.

Key words: Schnitzler syndrome. Autoinflamatory disease. Monoclonal gammopathy IgG.

\section{Introducción}

El síndrome de Schnitzler es una rara alteración autoinflamatoria adquirida, incluida entre los síndromes febriles periódicos. Dentro de sus síntomas figuran una erupción urticarial crónica, episodios febriles intermitentes, dolor óseo, artralgias y gammapatía monoclonal ( $90 \%$ IgM). Dado el polimorfismo clínico, las personas que lo padecen consultan a diversos especialistas médicos, como dermatólogos, reumatólogos y hematólogos antes de su diagnóstico final'.

La médica francesa Liliane Schnitzler describió la enfermedad en 1972 y hasta la fecha se han notificado unos 300 casos en las publicaciones médicas ${ }^{1-3}$. Se ha estudiado su fisiopatogenia pero todavía no es concluyente y se ha relacionado con mutaciones activadas del gen NLRP3, aumento de lipopolisacáridos que inducen el incremento de IL-1B por células mononucleares
Correspondencia:

*Lina P. González-Cardona

E-mail: linapgonzalezc@gmail.com
Disponible en internet: 06-10-2021 Med Cutan Iber Lat Am. 2021;49(Suppl 1):40-42 www.MedicinaCutanealLA.com 0210-5187/@ 2020 Colegio Ibero Latinoamericano de Dermatología A.C. (CILAD). Publicado por Permanyer. Este es un artículo open access bajo la licencia CC BY-NC-ND (http://creativecommons.org/licenses/by-nc-nd/4.0/). 
periféricas y aumento de la IL-6. Todavía no se ha dilucidado si la gammapatía monoclonal precede a la enfermedad o es consecuencia de ella ${ }^{4,5}$.

A continuación se presenta el caso de un paciente de 46 años, colombiano, con diagnóstico inicial de urticaria crónica resistente al tratamiento antihistamínico; los estudios clínicos posteriores establecieron el diagnóstico de síndrome de Schnitzler.

\section{Caso clínico}

Paciente masculino de 46 años que consulta por cuadro clínico de cuatro años de evolución que inicia con lesiones urticariformes con predominio en tronco, asintomáticas, de una duración aproximada de tres semanas. Los síntomas se exacerban en los dos últimos años: aumento de la gravedad de las lesiones de urticaria en relación con fiebre periódica cada tres semanas cuantificada hasta de $40^{\circ} \mathrm{C}$, artralgias con predominio en interfalángicas distales y pérdida de peso subjetiva. De modo inicial se determina el diagnóstico de urticaria crónica espontánea y se lo trata con antihistamínicos (loratadina y cetirizina) hasta cuatro veces y corticoides sistémicos sin mejoría. La exploración física muestra placas eritematoedematosas sobre todo en tórax, abdomen y extremidades con signo de Darier negativo y hepatomegalia (Fig. 1).

Como estudios de extensión se solicitó prueba histopatológica en piel que indicó epidermis ortoqueratósica y aplanada, dermis con un ligero aumento de la celularidad linfohistiocítica perivascular superficial, sin eosinófilos ni mastocitos. Los paraclínicos complementarios mostraron como hallazgos de importancia una proteína $C$ reactiva elevada y electroforesis de proteínas con una elevación monoclonal IgG-к (Tabla 1). De forma adicional se solicitaron tomografía axial computarizada (TAC) de cuello, abdomen y tórax, y gammagrafía ósea dentro de límites normales.

Se aplicaron los criterios de Lipsker para establecer el diagnóstico y se cumplieron todos los criterios; en consecuencia, en junta interdisciplinaria de los servicios de dermatología y reumatología se señaló el diagnóstico de síndrome de Schnitzel y se inició tratamiento con colquicina y prednisolona, con la posible adición de un antagonista del receptor IL-1B (canakinumab) en caso de falta de mejoría.

\section{Discusión}

Se presenta el caso clínico de un paciente con cuatro años de evolución de lesiones urticariformes, que

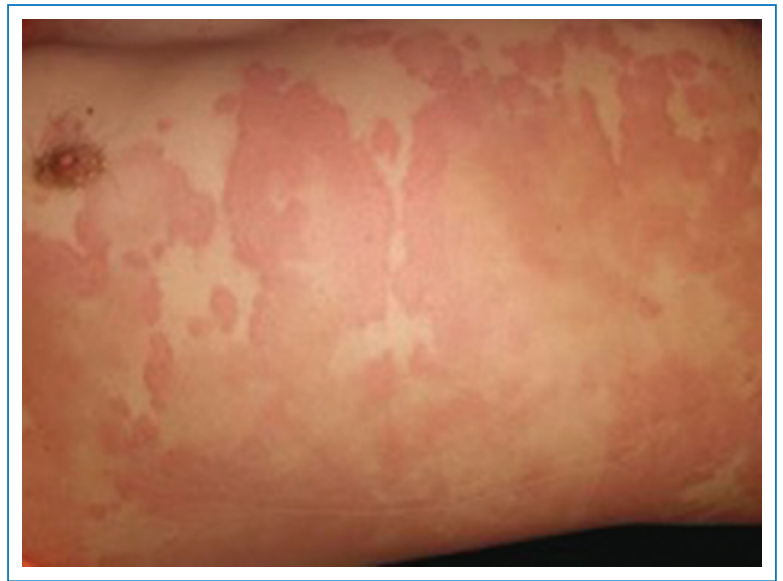

Figura 1. Urticaria en tórax y abdomen.

Tabla 1. Estudios paraclínicos que muestran un aumento de la PCR y gammapatía monoclonal de IgG-K

\begin{tabular}{|l|c|}
\hline Estudios paraclínicos & Leu: 5,$370 ; \mathrm{Hb}: 14.5 \mathrm{~g} / \mathrm{dL}$; Plt: \\
\hline Hemograma & 238,000
\end{tabular}

desarrolló con posterioridad síntomas sistémicos, resistencia al tratamiento con antihistamínicos y corticoides sistémicos, y que tras un lapso de unos dos años se diagnostica con síndrome de Schnitzel. Ésta es una entidad que se subdiagnostica en virtud de su baja prevalencia, escaso conocimiento clínico y ausencia de un biomarcador específico para determinar el diagnóstico, según lo confirmó un estudio retrospectivo de la Clínica de Mayo en el cual, según la base de datos de los pacientes con urticaria crónica y disproteinemias, se diagnosticaron 46 casos $^{6}$.

Respecto de su epidemiología, afecta a personas entre la cuarta y la quinta décadas de la vida, con predominio del género masculino y sin propensión 
étnica. En Latinoamérica sólo se han comunicado casos en Brasil, por lo cual resulta importante este informe de caso, ya que contribuye a la epidemiología del continente.

En su fisiopatogenia interviene en particular la IL-1B que suprime las propiedades antiinflamatorias de la IL-10 y la vía Th177. La IL-6 también juega un papel importante, dado que es un factor de crecimiento plasmático que se correlaciona con la actividad de la enfermedad al actuar como un reactante de fase aguda ${ }^{8}$. Es importante mencionar que se ha reconocido la participación de mutaciones no germinales en el gen NLRP3.

El diagnóstico es clínico y se caracteriza por fiebre recurrente, erupción urticarial, dolor en articulaciones o huesos, linfadenopatías, hepatomegalia y esplenomegalia; los estudios paraclínicos importantes para el diagnóstico son una PCR elevada, leucocitosis y gammapatía monoclonal, en la cual la lgM-к es la más frecuente en un $90 \%$ (sólo el $10 \%$ representa gammapatías monoclonales $\left.\lg \mathrm{G}^{1,9}\right)$. Por esta razón es importante tener en cuenta este tipo de gammapatía monoclonal para establecer el diagnóstico de síndrome de Schnitzler.

La histopatología revela un infiltrado dérmico neutrofílico, con un infiltrado perivascular e intersticial con leucocitoclastia; en el caso clínico presentado no hubo hallazgos histopatológicos relevantes, pero es parte de los criterios menores de Estrasburgo, por lo cual no es indispensable para el diagnóstico ${ }^{10}$.

Este caso clínico es el de un paciente de nacionalidad colombiana con cuadro clínico que inició con desarrollo de lesiones urticariales crónicas, con aparición posterior de fiebre periódica y cuyos estudios de extensión identificaron reactantes de fase aguda elevados y gammapatía monoclonal de compromiso incierto de IgG. Es importante este caso por la baja prevalencia del síndrome y su nexo con la gammapatía monoclonal IgG. El paciente inició tratamiento con colquicina y prednisolona, más canakinumab en caso de falta de respuesta.

\section{Financiamiento}

Los autores declaran no haber recibido financiamiento.

\section{Conflicto de intereses}

Los autores declaran no tener conflicto de intereses.

\section{Responsabilidades éticas}

Protección de personas y animales. Los autores declaran que para esta investigación no se han realizado experimentos en seres humanos ni en animales.

Confidencialidad de los datos. Los autores declaran que han seguido los protocolos de su centro de trabajo sobre la publicación de datos de pacientes.

Derecho a la privacidad y consentimiento informado. Los autores han obtenido el consentimiento informado de los pacientes o sujetos referidos en el artículo. Este documento obra en poder del autor de correspondencia

\section{Bibliografía}

1. Gusdorf L, Lipsker D. Schnitzel syndrome: a review. Curr Rheumatol Rep. 2017;19:46.

2. De Koning HD. Schnitzler's syndrome: lessons from 281 cases. Clinical and Translational Allergy. 2014;4:41

3. Schnitzler L. Lésions urticariennes chroniques permanentes (érithème pétaloïde?). Journées Dermatologiques d’Angers. 1972; Cas Clinique. N46b.

4. De Koning HD, Schalkwijk J, Stoffels M. The role of interleukin-1 beta in the pathophysiology of Schnitzler's syndrome. Arthritis Res Ther. 2015;17:187.

5. Lipsker D. Monoclonal gammopathy of cutáneos significance: review of a relevant concept. J Eur Acad Dermatol Venereol. 2017;31:45-52.

6. Jain T, Offord CP, Kyle RA. Schnitzler syndrome: an under-diagnosed clinical entity. Haematologica. 2013 98:1581-1585.

7. Zielinski CE, Mele F, Aschenbrenner D. Pathogen-induced human TH17 cells produce IFN-gamma or IL-10 and are regulated by. Nature. 2012;484:514-8

8. De Koning HD, van Vlijmen-Willwms IMJJ, Rodijk-Olthuis D. Mast-cell interleukin-1beta, neutrophil interleukin-17 and epidermal antimicrobial proteins in the neutropjilic urticarial dermatosis in Schnitzler's syndrome. Br J Dermatol. 2015;173:448-56.

9. Lipsker D. The Schnitzler syndrome. Orphanet Journal of Rare Diseases. 2010;5:38.

10. Kieffer C, Cribier B, Lipsker D. Neutrophilic urticarial dermatosis: a variant of neutrophilic urticaria strongly associated with systemic disease. Report of 9 new cases and review of the literature. Medicine (Baltimore). 2009;88:23-31. 